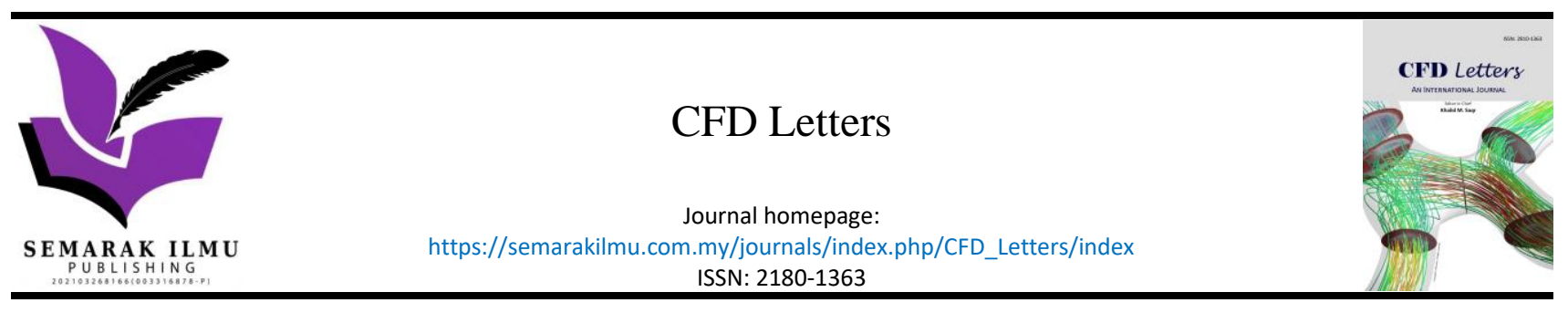

\title{
Effect of Angle of Turn on Loss Characteristics and Flow Rectification of Curve Diffuser
}

\author{
Hau Chin Yong ${ }^{1}$, Normayati Nordin ${ }^{1,}{ }^{*}$, Shamsuri Mohamed Rasidi ${ }^{1}$, Teo Wen Yong ${ }^{1}$, Muhammad \\ Musleh Anuar ${ }^{1}$, Muhammad Zahid Firdaus Shariff ${ }^{1}$
}
Centre for Energy and Industrial Environment Studies, Faculty of Mechanical and Manufacturing Engineering, Universiti Tun Hussein Onn Malaysia, 86400 Parit Raja, Malaysia

\section{ARTICLE INFO}

\section{Article history:}

Received 5 October 2021

Received in revised form 14 December 2021

Accepted 15 December 2021

Available online 7 January 2022

\section{Keywords:}

Curve diffuser; Pressure Recovery; Flow Uniformity; Angle of Turn

\section{ABSTRACT}

Curve diffuser is often used in HVAC and wind tunnel systems to provide pressure recovery and avoid excessive energy loss to the surrounding environment. Performance of curve diffuser is disturbed mainly by the presences of flow separation and secondary flow vortices occurred due to the effect of turning angle, in which scarce literature found. In this study, the effect of turning angle from $30^{\circ}$ to $180^{\circ}$ configured with an area ratio of 1.60 to 4.00 and inflow Reynolds number of $5.934 \times 10^{4}-1.783 \times 10^{5}$ on loss characteristics and flow rectification of curve diffuser is investigated with optimum configuration is proposed. Performance of curve diffuser is evaluated in terms of pressure recovery and flow uniformity using ANSYS CFD equipped with validated Standard $\mathrm{k}-\varepsilon$ model (ske) and enhanced wall treatment of $\mathrm{y}^{+}=1.2-1.7$. Results show that performance of pressure recovery and flow uniformity decreases respectively by $85.71 \%$ and $45.84 \%$ as the angle of turn increases from $30^{\circ}$ to $180^{\circ}$. Curve diffuser with minimum angle of turn $30^{\circ}$, optimum area ratio 2.16 and intermediate $\operatorname{Re}_{\text {in }} 8.163 \times 10^{4}$ turns out to be the best configuration to provide pressure recovery of 0.399 and flow uniformity of $3.630 \mathrm{~m} / \mathrm{s}$.

\section{Introduction}

Curve diffuser is an engineering fluid device with combined features of bending and spreading that is often used in HVAC and wind tunnel systems as a fluid flow speed reducer. The basic mechanism is by converting kinetic energy to pressure energy in which could be achieved by altering the geometrical and operating parameters such as area ratio $(A R)$, curvature length $\left(L_{\text {in }} / W_{1}\right)$, angle of turn $(\Delta \phi)$, turbulent intensity $(\mathrm{I})$ and inflow Reynolds number $\left(\operatorname{Re}_{\text {in }}\right)$ optimally [1-2].

The angle of turn was found to affect the performance of the curved diffuser yet has not been comprehensively studied. Fox and Kline [1] proposed that $90^{\circ}$ angle of turn should be configured with an area ratio not greater than 2.0 to avoid massive flow separation. However, in some circumstances there would be no relaxation in terms of geometrical selection in spite of a debatable performance owing to design and space constraints. For instance, on account of a space

\footnotetext{
* Corresponding author.

E-mail address: mayati@uthm.edu.my (Normayati Nordin)
} 
limitation, a $90^{\circ}$ curve diffuser with an extremely short inner wall length $\left(L_{\text {in }} / W_{1}=2.6\right)$ and large area ratio $(A R=3.9)$ was designed, though unfavorable for a blow-down wind tunnel system [3]. Despite a deficient performance, an $180^{\circ}$ curve diffuser with inner wall expansion and large $A R=4.0$ was still introduced for a wind tunnel application due to a design restriction [4]. The flow separation occurred in the curve diffuser due to sharp inflection to cause the boundary layer to thicken thus increasing the pressure gradient. This strong adverse pressure gradient is that fails the flow to escalate and detach from the wall to form separation. It is an undesirable phenomenon to associate with an increase of form drag, reduction of core flow area, damage of downstream equipment, generation of noise and structural vibration [5-6].

High $\mathrm{Re}_{\text {in }}$ is expected to produce a relatively thin boundary layer allowing the flow to adhere to the wall. However, there is an additional characteristic for fluid that flows over a curved surface at an excessive velocity. The fluid is likely to separate from the wall at a certain point to form the separated region. An applicable $\mathrm{Re}_{\text {in }}$ should be therefore decided to provide less flow disruption. $\operatorname{Re}_{\text {in }}$ was proven by Nordin et al., [5-9] to affect the performance of $90^{\circ}$ curve diffuser, with 3D expansion yielded higher pressure recovery than $2 \mathrm{D}$ expansion, when was operated at low $\operatorname{Re}_{\text {in }}=5.786 \times 10^{4}$ $6.382 \times 10^{4}$. Xian et al., [8] has developed performance correlations of curve diffuser to integrate effects of turning angle, however less discussion was given on turning angle effects configured with other important parameters in turns.

In the present work, the effects of turning angle on flow rectification and loss characteristics are comprehensively investigated using Computational Fluid Dynamics (CFD). Curve diffusers with an angle of turn $\left(30^{\circ}, 90^{\circ}, 120^{\circ}, 150^{\circ}, 180^{\circ}\right)$, area ratio $(1.60,2.16,4.00)$ and inflow Reynolds number $\left(5.934 \times 10^{4}, 8.163 \times 10^{4}, 1.783 \times 10^{5}\right)$ are considered. These ranges of variables are opted to serve common operating settings of curve diffuser for subsonic applications such as wind tunnel and HVAC systems [3-19].

\section{Numerical Method}

ANSYS CFD code FLUENT version 19.2 was used as a tool to simulate the effects of turning angle on curve diffuser performance. Figure 1 illustrates the overall CFD workflow that involves preprocessing, processing, and post-processing phases. Three (3) turbulence models (Standard k- $\varepsilon$, Renormalization Group $k-\varepsilon$ and Realizable k-epsilon) adopted enhanced wall treatment were considered for the validation. A turbulence model that could provide the least discrepancies with similarity of flow characteristics to the experimental case $[10-12,14-16]$ was chosen for the intensive simulation. 


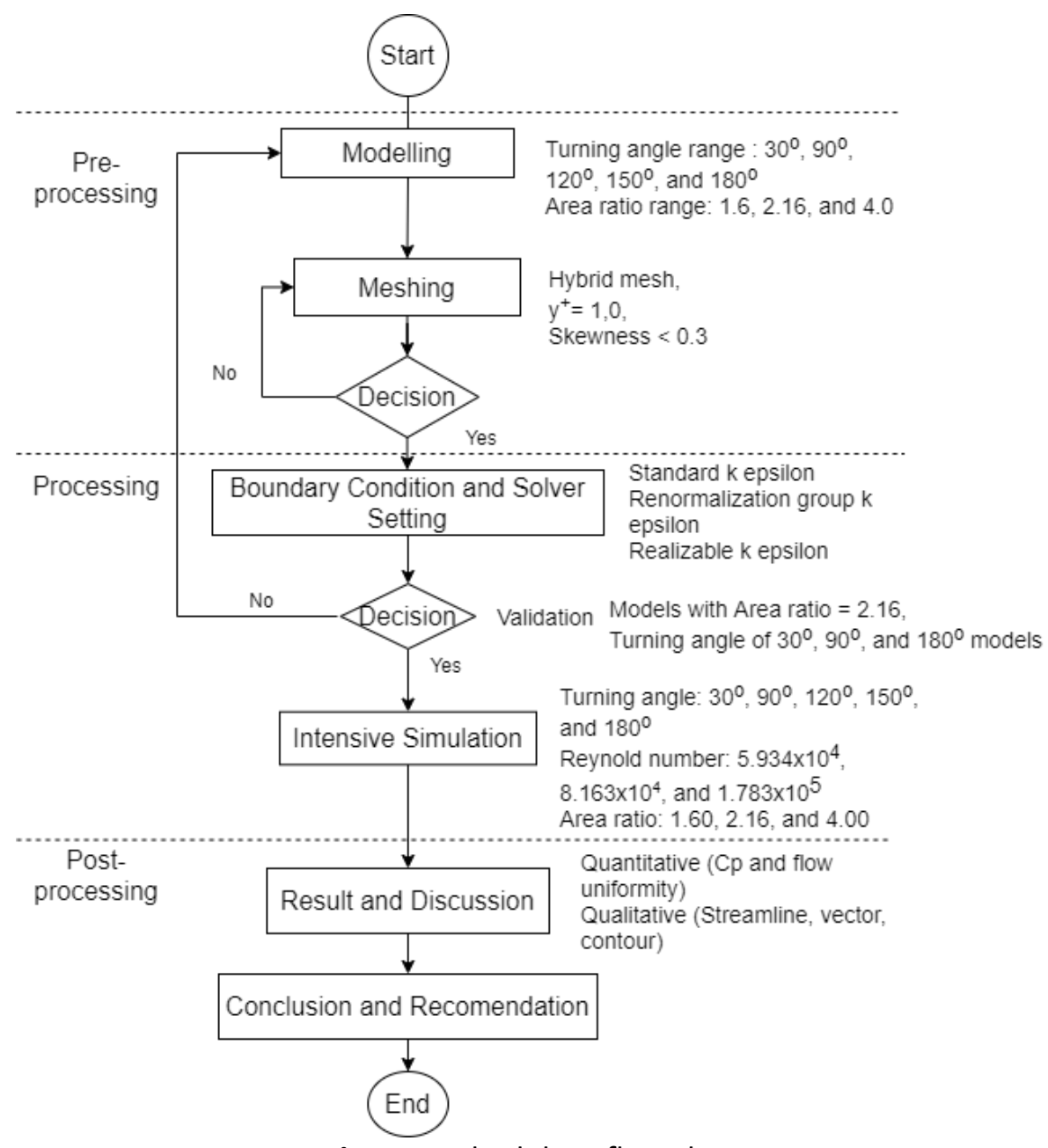

Fig. 1. Methodology flow chart

\subsection{Modelling and Meshing}

Curve diffusers with turning angles from $30^{\circ}$ to $180^{\circ}$ were modelled as shown in Table 1 in which each to configure area ratio of 1.6 to 4.0. As shown in Figure 2, hybrid mesh to consist of hexahedral and tetrahedral elements was generated to provide acceptable quality of skewness $0.3[5-9,12]$. Enhanced wall treatment of $\mathrm{y}^{+}=1.2-1.7$ was applied to allow an optimum number of nodes obtained particularly close to the inner wall region to capture presences of flow separation. Failure in observing this essential flow phenomenon may disrupt the results as a whole.

A grid independency test was conducted to verify the optimum mesh to represent the actual case. As presented in Table 2, Mesh 4 provides the least deviation relative to the finest mesh within reasonable CPU solving time opted as the most optimum setting. 
CFD Letters

Volume 14, Issue 1 (2022) 38-51

\section{Table 1}

Curve Diffuser Models
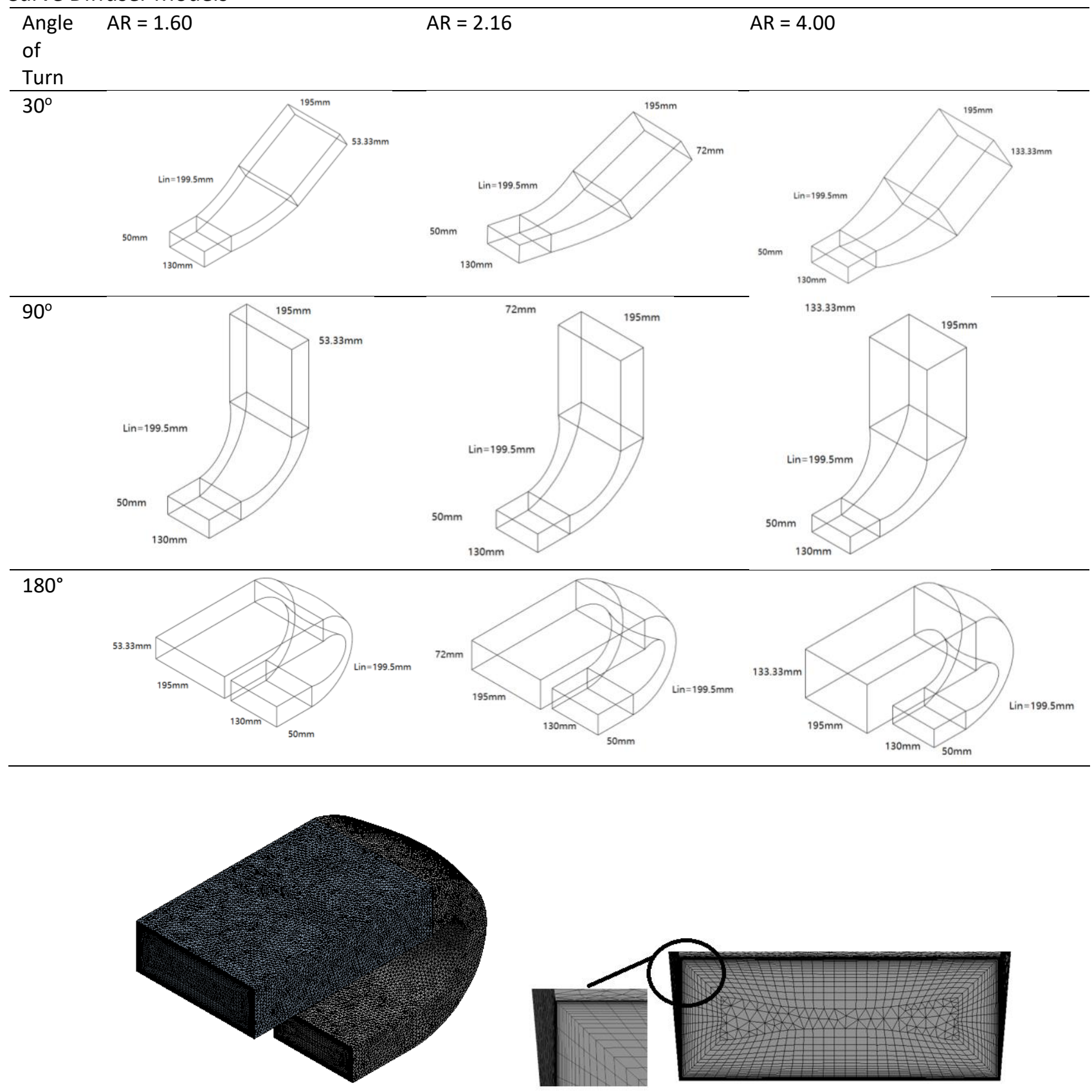

Fig. 2. Mesh generation 
Table 2

Grid independency test

\begin{tabular}{|c|c|c|c|c|c|}
\hline $\begin{array}{l}\text { Turning } \\
\text { Angle }\end{array}$ & $\begin{array}{l}\text { Reynold } \\
\text { Number }\end{array}$ & Mesh & Elements & $\begin{array}{l}\text { Pressure } \\
\text { Recovery, Cp }\end{array}$ & Deviation, \% \\
\hline \multirow[t]{5}{*}{$30^{\circ}$} & $1.07 \times 10^{5}$ & 1 & 860055 & 0.3663 & 10.90 \\
\hline & & 2 & 952692 & 0.3842 & 6.54 \\
\hline & & 3 & 1044156 & 0.3783 & 7.98 \\
\hline & & 4 & 1154569 & 0.3977 & 3.26 \\
\hline & & 5 & 1312237 & 0.4111 & - \\
\hline \multirow[t]{5}{*}{$90^{\circ}$} & $1.82 \times 10^{5}$ & 1 & 595146 & 0.2785 & 7.54 \\
\hline & & 2 & 645575 & 0.2956 & 7.86 \\
\hline & & 3 & 697310 & 0.2744 & 8.90 \\
\hline & & 4 & 762407 & 0.2942 & 2.32 \\
\hline & & 5 & 830109 & 0.3012 & - \\
\hline \multirow[t]{5}{*}{$180^{\circ}$} & $1.70 \times 10^{5}$ & 1 & 1523621 & 0.0871 & 11.48 \\
\hline & & 2 & 1604019 & 0.0923 & 6.20 \\
\hline & & 3 & 1728412 & 0.0986 & 0.20 \\
\hline & & 4 & 1814320 & 0.0986 & 0.20 \\
\hline & & 5 & 1849297 & 0.0984 & - \\
\hline
\end{tabular}

\subsection{Solver and Boundary Condition Settings}

The following three-dimensional steady-state Reynolds Averaged Navier Stokes (RANS) equations were numerically solved for a Newtonian, incompressible fluid. The flow was assumed to be fully developed, steady-state and isothermal. The gravitational effect was negligible.

Continuity equation

$\frac{\partial u}{\partial x}+\frac{\partial v}{\partial y}+\frac{\partial w}{\partial z}=0$

$\mathrm{X}$-momentum equation

$u \frac{\partial u}{\partial x}+v \frac{\partial u}{\partial y}+w \frac{\partial u}{\partial z}=-\frac{1}{p} \frac{\partial p}{\partial x}+v\left[\frac{\partial^{2} u}{\partial x^{2}}+\frac{\partial^{2} u}{\partial y^{2}}+\frac{\partial^{2} u}{\partial z^{2}}\right]+\frac{1}{p}\left[\frac{\partial\left(-p \overline{\left.u^{\prime 2}\right)}\right.}{\partial x}+\frac{\partial\left(-p \overline{\left.u^{\prime} v^{\prime}\right)}\right.}{\partial y}+\frac{\partial\left(-p \overline{\left.u^{\prime} w^{\prime}\right)}\right.}{\partial z}\right]$

Y-momentum equation

$u \frac{\partial v}{\partial x}+v \frac{\partial v}{\partial y}+w \frac{\partial v}{\partial z}=-\frac{1}{p} \frac{\partial p}{\partial y}+v\left[\frac{\partial^{2} v}{\partial x^{2}}+\frac{\partial^{2} v}{\partial y^{2}}+\frac{\partial^{2} v}{\partial z^{2}}\right]+\frac{1}{p}\left[\frac{\partial\left(-p \overline{\left.u^{\prime} v^{\prime}\right)}\right.}{\partial x}+\frac{\partial\left(-p \overline{v^{\prime 2}}\right)}{\partial y}+\frac{\partial\left(-p \overline{\left.v^{\prime} w^{\prime}\right)}\right.}{\partial z}\right]$

Z-momentum equation

$u \frac{\partial w}{\partial x}+v \frac{\partial w}{\partial y}+w \frac{\partial w}{\partial z}=-\frac{1}{p} \frac{\partial p}{\partial z}+v\left[\frac{\partial^{2} w}{\partial x^{2}}+\frac{\partial^{2} w}{\partial y^{2}}+\frac{\partial^{2} w}{\partial z^{2}}\right]+\frac{1}{p}\left[\frac{\partial\left(-p \overline{\left.u^{\prime} w^{\prime}\right)}\right.}{\partial x}+\frac{\partial\left(-p \overline{\left.v^{\prime} w^{\prime}\right)}\right.}{\partial y}+\frac{\partial\left(-p \overline{w^{\prime 2}}\right)}{\partial z}\right]$

As depicted in Table 3, three types of boundary operating conditions were imposed. The inlet velocity, $V_{\text {in }}$ was varied in the range 13.26 to $39.83 \mathrm{~m} / \mathrm{s}$ corresponding to the $R_{e}$ in $=5.934 \times 10^{4}-$ $1.783 \times 10^{5}$ and $I_{\text {in }}=3.7-4.1$. At the outlet boundary, the pressure was set at atmospheric pressure ( 0 gage pressure). At the solid wall, the velocity was zero due to the no-slip condition.

Table 4 lists the details of solver setting applied. The governing equations were independently solved using a double-precision pressure-based solver with a robust pressure-velocity coupling algorithm, SIMPLE been applied. To reduce numerical diffusion, the QUICK scheme was employed for the discretization of the momentum equations, the turbulent kinetic energy equation, and the 
turbulent dissipation rate equation. A PRESTO discretization scheme was applied for the continuity equation and a default scheme, i.e. Green-Gauss Cell-based, was employed for the solution of the gradient. Three k- $\varepsilon$ turbulence models (ske, rngke, rke) were considered to simulate the case with the best model opted from validation.

\section{Table 3}

Boundary condition for operating parameter

\begin{tabular}{lll}
\hline Inlet & Type of boundary & Velocity inlet \\
& Velocity magnitude, $\mathrm{V}_{\text {in }}(\mathrm{m} / \mathrm{s})$ & $13.26 \mathrm{~m} / \mathrm{s}\left(5.934 \times 10^{4}\right)$ \\
& & $18.23 \mathrm{~m} / \mathrm{s}\left(8.162 \times 10^{4}\right)$ \\
& & $39.83 \mathrm{~m} / \mathrm{s}\left(1.783 \times 10^{5}\right)$ \\
& Turbulent intensity, lin $(\%)$ & 4.1 \\
& & 3.9 \\
& & 3.7 \\
& Hydraulic diameter, $\mathrm{D}_{\mathrm{h}}(\mathrm{mm})$ & 72 \\
\hline Outlet & Type of boundary & Pressure outlet \\
& Pressure $(\mathrm{Pa})$ & Zero-gauge pressure \\
\hline Wall & Type of boundary & Smooth wall \\
& Shear condition & No-slip condition \\
\hline Working Fluid Properties & Working fluid & Air \\
& Temperature $\left({ }^{\circ} \mathrm{C}\right)$ & 30 \\
& Density, $\rho\left(\mathrm{kg} / \mathrm{m}^{3}\right)$ & 1.164 \\
& Dynamic viscosity, $\mu(\mathrm{kg} / \mathrm{m} . \mathrm{s})$ & $1.872 \times 10^{-5}$ \\
\hline
\end{tabular}

\section{Table 4}

Solver details

\begin{tabular}{ll}
\hline Solver Scheme & SIMPLE \\
Gradient & Green-Gauss Cell Based \\
Pressure & PRESTO \\
Momentum & QUICK \\
Turbulent Kinetic Energy & QUICK \\
Turbulent Dissipation Rate & QUICK \\
Turbulence models & Standard k- $\varepsilon$ (ske) model \\
& Renormalization Group k- $\varepsilon$ (Rngke) model \\
& Realizable k- $\varepsilon$ (rke) model \\
\hline
\end{tabular}

Pressure recovery coefficient $\left(C_{p}\right)$ and flow uniformity index ( $\sigma_{\text {out }}$ ) are the parameters used to assess the performance [5-17]:

$C p=\frac{2\left(P_{\text {out }}-P_{\text {in }}\right)}{\rho V_{\text {in }}^{2}}$

where,

$\mathrm{P}_{\text {out }}=$ Average static pressure at outlet $(\mathrm{Pa})$

$P_{\text {in }}=$ Average static pressure at inlet $(\mathrm{Pa})$

$\rho=$ Air density $\left(\mathrm{kg} / \mathrm{m}^{3}\right)$

$V_{\text {in }}=$ Mean air velocity at inlet $(\mathrm{m} / \mathrm{s})$

$\sigma_{\text {out }}=\sqrt{\frac{1}{N-1} \sum_{i=1}^{N}\left(V_{i}-V_{\text {out }}\right)^{2}}$ 
where,

$\mathrm{N}=$ Number of measurement points

$V_{i}=$ Local air velocity at outlet $(\mathrm{m} / \mathrm{s})$

$V_{\text {out }}=$ Mean air velocity at outlet $(\mathrm{m} / \mathrm{s})$

The $\mathrm{Cp}$ indicates how much kinetic energy is successfully converted to pressure energy. The main problem in achieving high pressure recovery is flow separation, which results in dissipation of energy and non-uniform flow distribution [20-22]. The $\sigma_{\text {out }}$ is used to measure the dispersion of local velocity from the mean velocity. It is strongly dependent on the distribution of the core flow and the presence of secondary flow. The flow is considered uniform with the presence of secondary flow of less than $10 \%$ [23-25].

\subsection{Numerical Validation}

For validation, $30^{\circ}, 90^{\circ}$ and $180^{\circ}$ curve diffusers of area ratio 2.16 were considered. Previous experimental work by Rasidi et al., [11] was referred to validate the best turbulence model to represent the case. As shown in Table 5, all k- $\varepsilon$ solver models show promising potential except for rke and rngke to provide unconverged solution for $180^{\circ}$. Due to stability and accuracy, ske model was therefore chosen, providing a deviation of less than $5 \%$.

Table 5

Numerical validation

\begin{tabular}{lllll}
\hline Turning angle & Turbulence models & \multicolumn{2}{l}{ Pressure recovery coefficient, Cp } & Deviation, \% \\
\cline { 3 - 4 } & & Numerical & Experiment [9] & \\
\hline $30^{\circ}$ & ske & 0.383 & & 2.54 \\
& rke & 0.368 & 0.393 & 6.36 \\
$90^{\circ}$ & rngke & 0.388 & & 1.09 \\
& ske & 0.281 & & 0.71 \\
& rke & 0.267 & 0.283 & 5.65 \\
$180^{\circ}$ & rngke & 0.307 & & 8.48 \\
& ske & 0.035 & & 2.94 \\
& rke & - & 0.034 & - \\
\hline
\end{tabular}

\section{Results and Discussion}

Effects of turning angle configured with different area ratios and inflow Reynold number on pressure recovery and flow uniformity are assessed. Ultimately, the most optimum configuration is proposed.

\subsection{Effect of Angle of Turn}

Table 6 presents the results of varying angle of turn from $30^{\circ}$ to $180^{\circ}$ on pressure recovery and flow uniformity. It shows that pressure recovery decreases by approximately $85.71 \%$ with the increase of turning angle to $180^{\circ}$. As observed in Figure 3, the wide-angle of turns is relatively more susceptible to excessive flow separation. Due to the abrupt inflection and strong adverse pressure gradient, the flow in $180^{\circ}$ curve diffuser loses its energy, thus detaches from the inner wall to form flow separation and vortices. This separation is often associated with the form drag that could considerably affect the recovery. Furthermore, the core flow area is also disrupted by the presence 
of separation to produce severe flow uniformity of $45.84 \%$ when the angle increases to the widest. It is worth noted that the higher the $\sigma_{\text {out, }}$ the severer the flow uniformity.

Table 6

Effect of turning angle on pressure recovery and flow uniformity

\begin{tabular}{lll}
\hline Turning angle & Pressure recovery coefficient, $\mathrm{Cp}$ & Flow uniformity index, $\sigma_{\text {out }}$ \\
\hline 30 & 0.399 & 3.630 \\
90 & 0.266 & 3.887 \\
120 & 0.157 & 4.304 \\
150 & 0.127 & 4.800 \\
180 & 0.057 & 5.294 \\
\hline
\end{tabular}
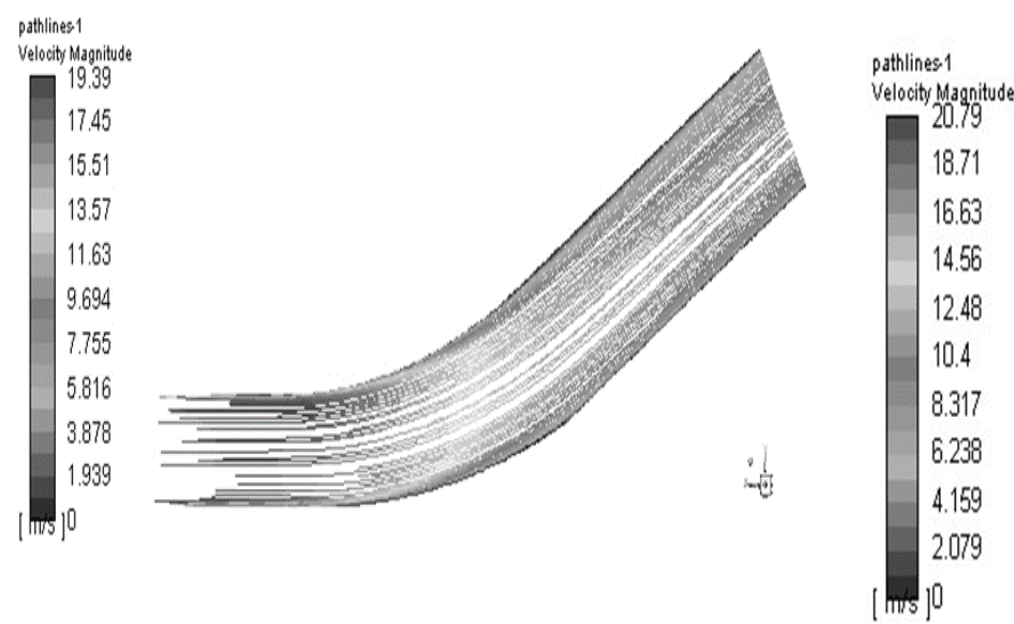

(a)

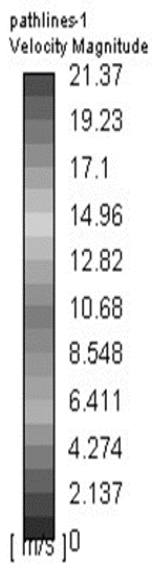

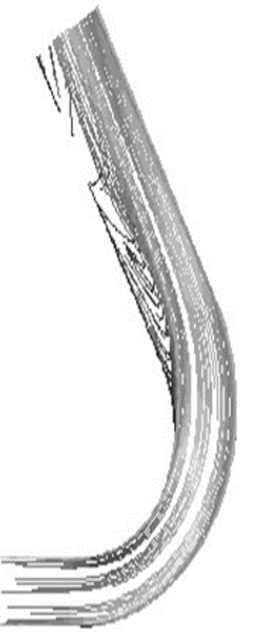

(c)

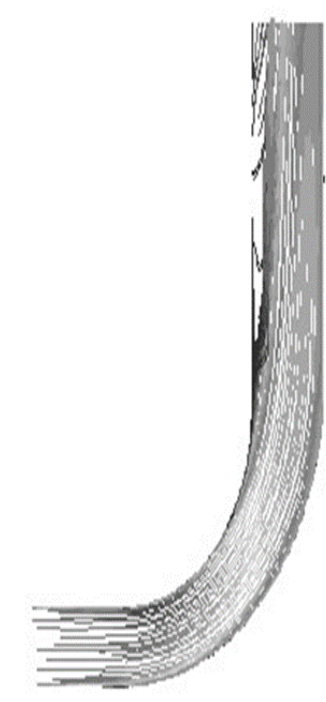

(b)

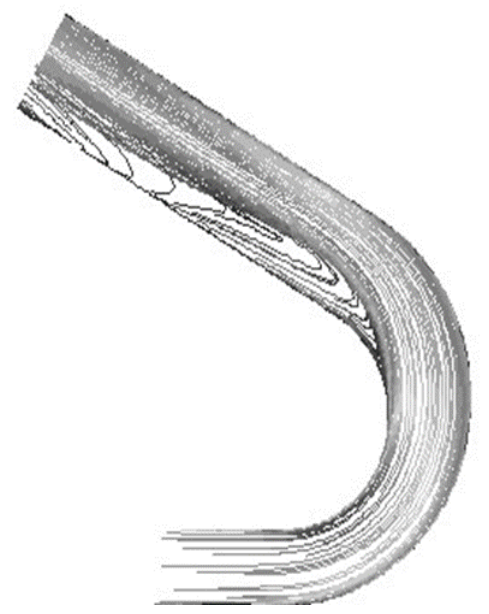

(d) 

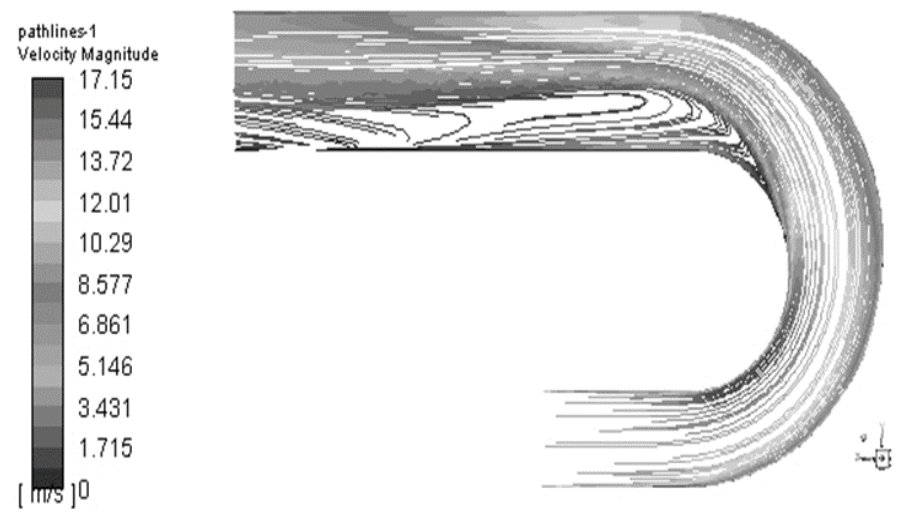

(e)

Fig. 3. Velocity streamline of (a) $30^{\circ}$, (b) $90^{\circ}$, (c) $120^{\circ}$, (d) $150^{\circ}$ and (e) $180^{\circ}$ curve diffuser

\subsection{Effect of Inflow Reynolds Number}

Figure 4 shows the results of varying $\operatorname{Re}_{\text {in }}$ from $5.934 \times 10^{4}$ to $1.783 \times 10^{5}$ on pressure recovery and flow uniformity for different angle of turn. Pressure recovery is found to improve for all angle of turn with the increase of $\operatorname{Re}_{\text {in }}$ from $5.934 \times 10^{4}$ to $8.163 \times 10^{4}$. However, a further increase to $R e_{\text {in }}=1.783 \times 10^{5}$ slightly disrupts the recovery performance. As shown in Figures 5 and 6 , as the $\operatorname{Re}_{\text {in }}$ increased, the fluid inertia becomes more important in which at some location particularly for $180^{\circ}$ angle of turn, the fluid inertia cannot follow the curved path. Some of the fluid would flow against the direction of upstream, i.e., back flow to form separation and vortices. This unfavourable flow condition due to bluntly increase the $\mathrm{Re}_{\text {in }}$ not only affects the recovery but also flow uniformity up to $200 \%$. To seek a compromise between pressure recovery and flow uniformity, a curve diffuser with a minimal angle of turn $30^{\circ}$, operated at an intermediate $\mathrm{Re}_{\text {in }}$ of $8.163 \times 10^{4}$ should be opted.

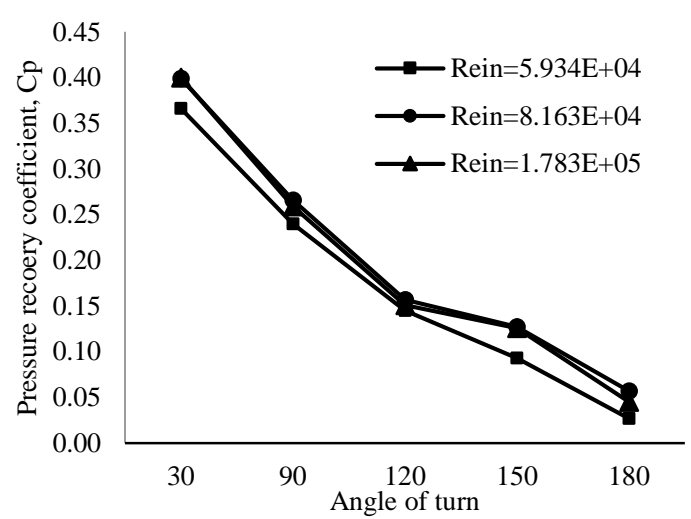

(a)

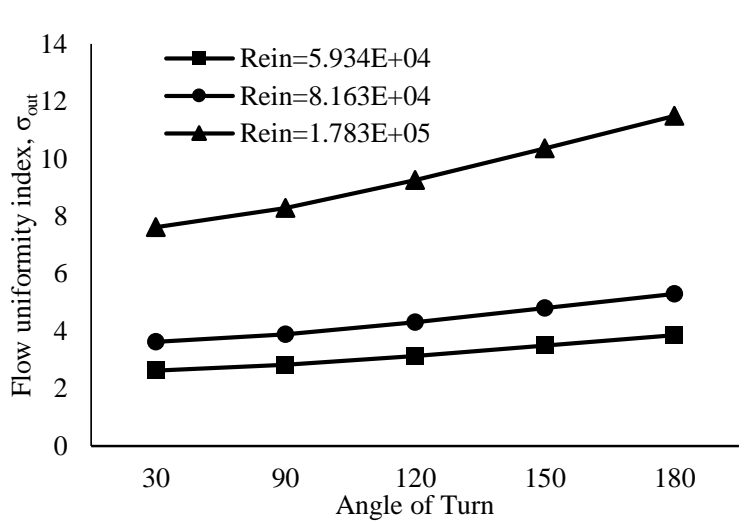

(b)

Fig. 4. Effect of inflow Reynolds Number on (a) pressure recovery and (b) flow uniformity for different angle of turn 


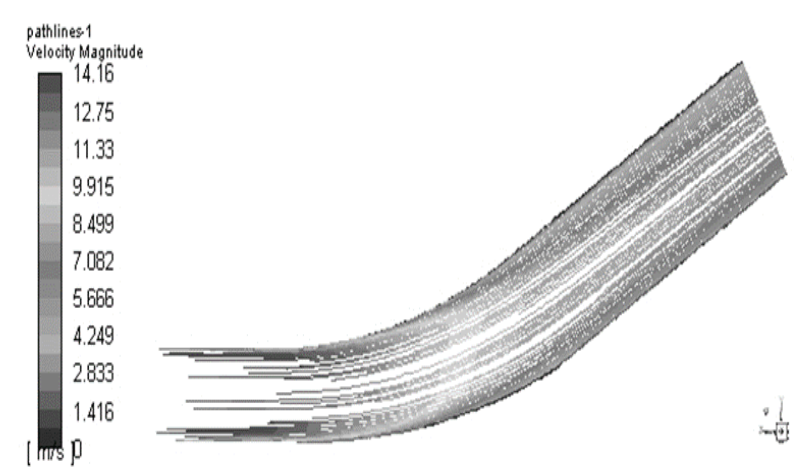

(a)

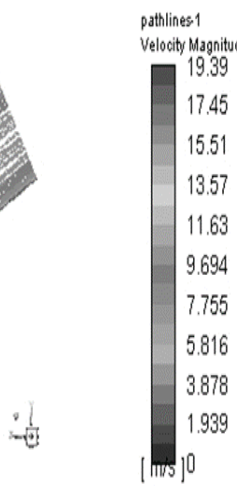

Velocity Magnitu

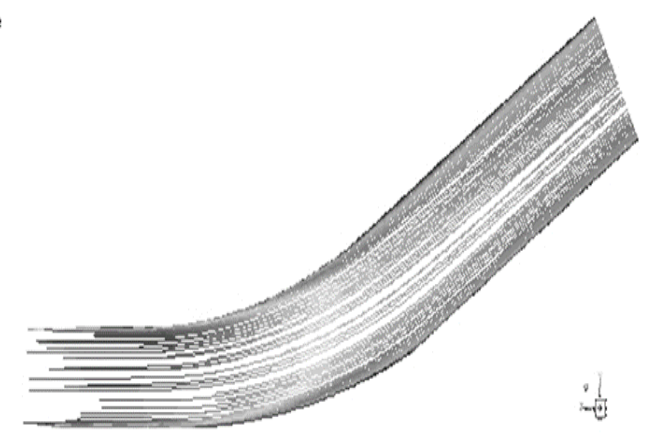

(b)

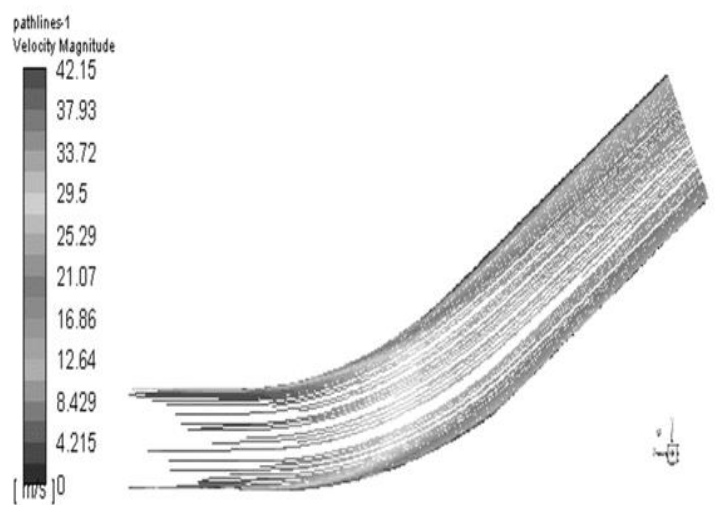

(c)

Fig. 5. Velocity streamline of $30^{\circ}$ curve diffuser at $\operatorname{Re}_{\text {in }}(\mathrm{a}) 5.934 \times 10^{4}$, (b) $8.163 \times 10^{4}$, and (c) $1.783 \times 10^{5}$

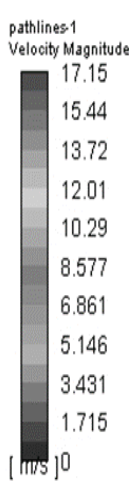

(c)

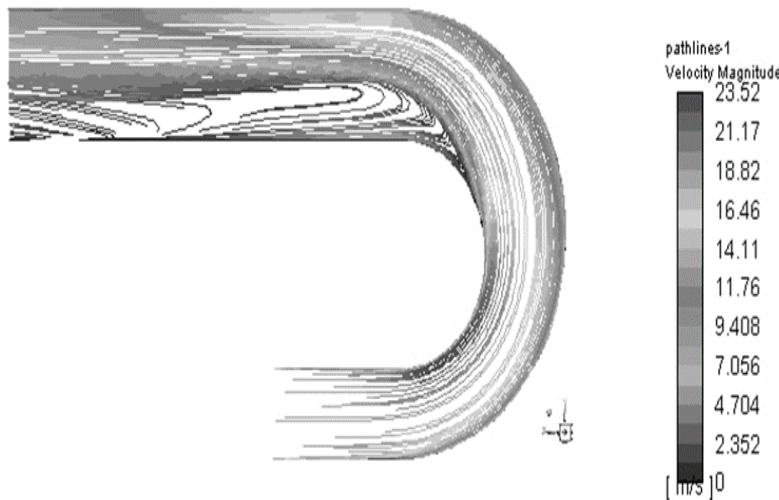

(a)

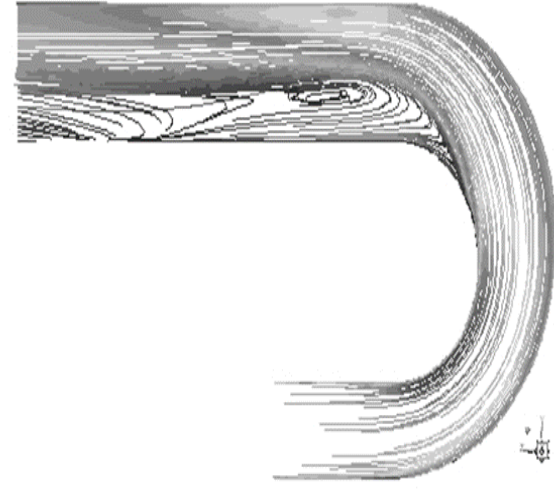

(b)

Pettlines1
Velocity Magnitude
51.14
46.02
40.91
35.79
30.68
25.57
20.45
15.34
10.23
5.114
[mis $]^{0}$

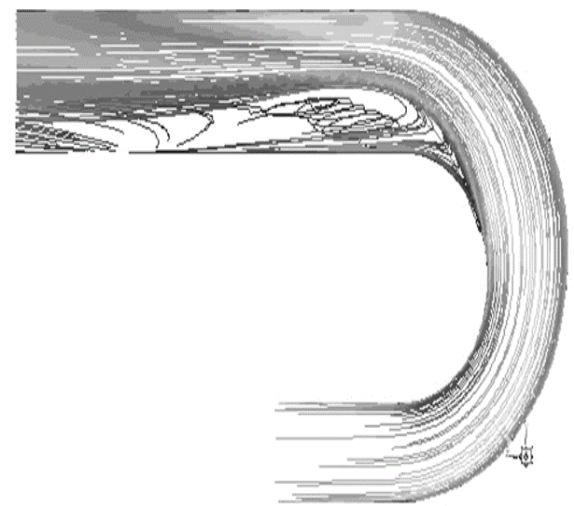

Fig. 6. Velocity streamline of $180^{\circ}$ curve diffuser at $\operatorname{Re}_{\text {in }}(\mathrm{a}) 5.934 \times 10^{4}$, (b) $8.163 \times 10^{4}$, and (c) $1.783 \times 10^{5}$ 


\subsection{Effect of Area Ratio}

Figure 7 shows the effects of varying area ratios from 1.60 to 4.00 on pressure recovery and flow uniformity of different angle of turn operated at $\mathrm{Re}_{\text {in }}=8.163 \times 10^{4}$. Fundamentally, pressure is gained when the area expands. As seen in Figure $7(a)$, the $C_{p}$ improves significantly with the increase of $A R$ from 1.60 to 2.16 , to the maximum $C_{p}=0.399$ for $30^{\circ}$ angle of turn. Nevertheless, further increase of AR to 4.00 drops the recovery due to massive stall occurred within the inner-wall region (See Figures 8 and 9). There is an unprecedented result of favourable flow uniformity obtained for $A R=4.00$ despite the excessive separation. This is deemed to happen due to turbulence effects and the presence of secondary flow vortices at the outlet that assist mixing of flow $[9,19]$. Hence, $A R=2.16$ is chosen as it could produce great recovery of pressure and permissible flow rectification.

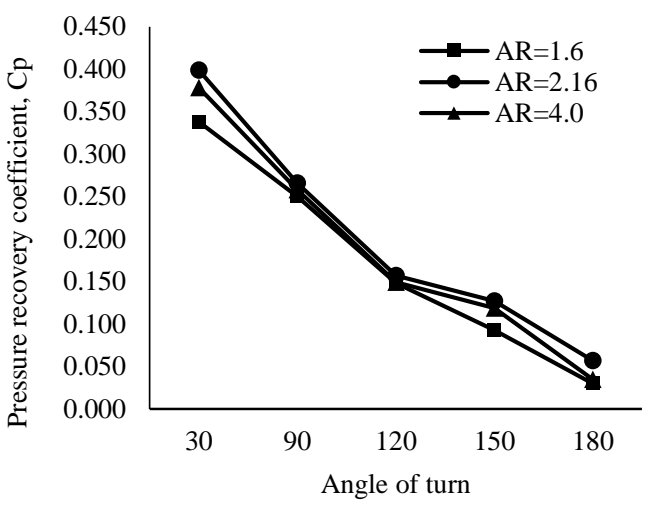

(a)

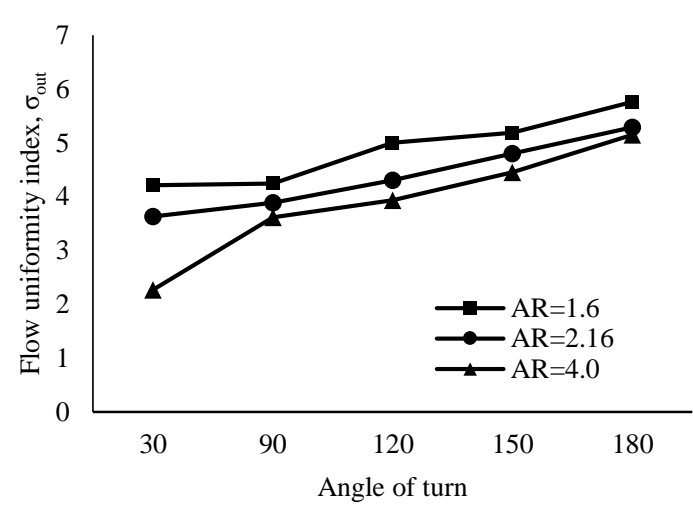

(b)

Fig. 7. Effect of area ratio on (a) pressure recovery and (b) flow uniformity for different angle of turn at $\operatorname{Re}_{\text {in }}=8.163 \times 10^{4}$

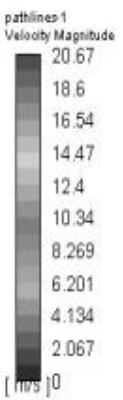

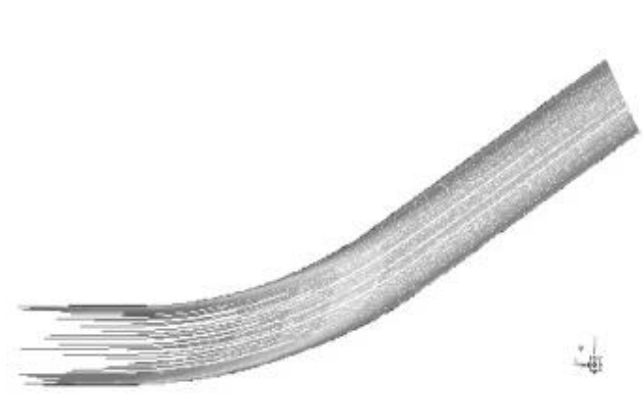

(a)
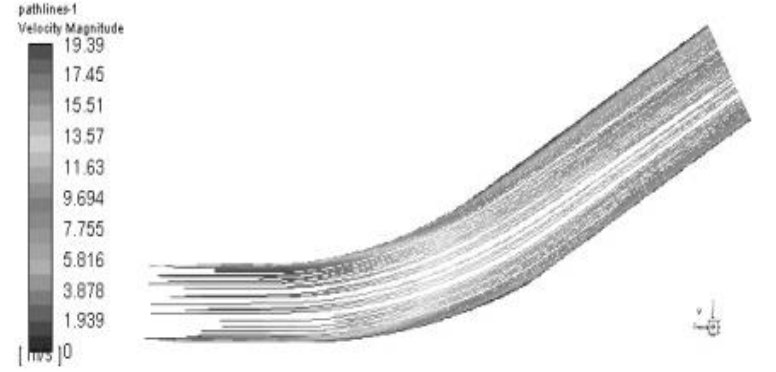

(b)
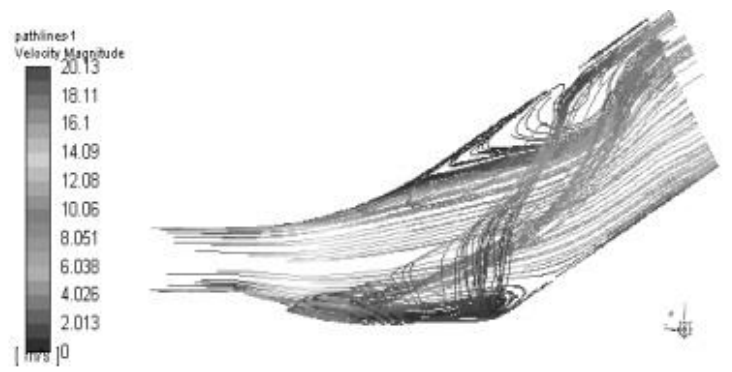

(c)

Fig. 8. Velocity streamline of $30^{\circ}$ curve diffuser at area ratio of (a) 1.60 , (b) 2.16 and (c) 4.00 

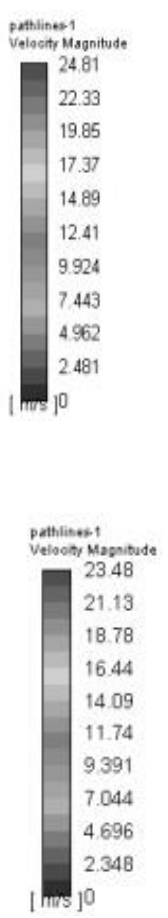

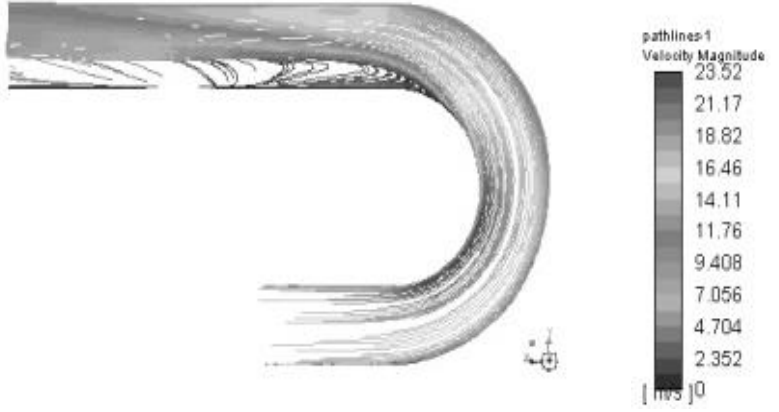

(a)

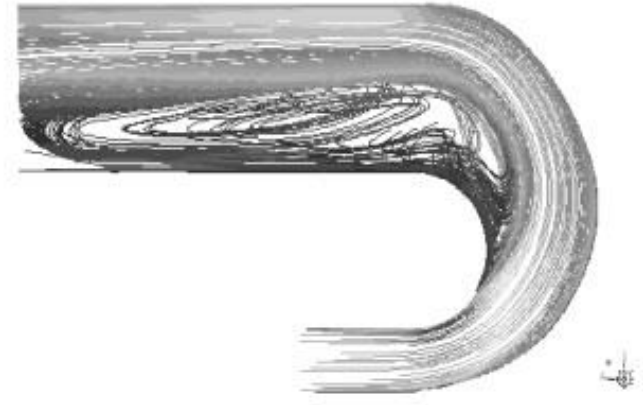

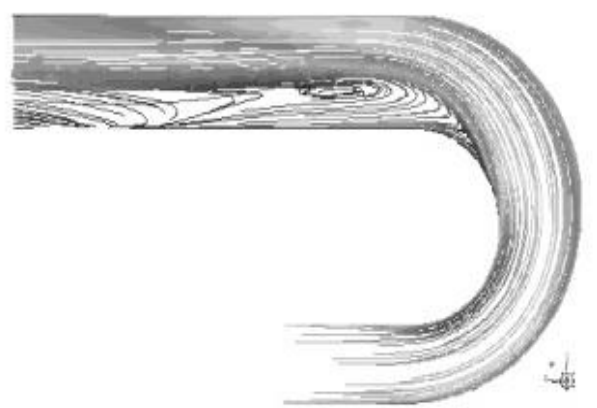

(b)

(c)

Fig. 9. Velocity streamline of $180^{\circ}$ curve diffuser at area ratio of (a) 1.60 , (b) 2.16 and (c) 4.00

\subsection{Optimum Configuration}

Based on the results and discussion made previously, a curve diffuser with $30^{\circ}$ angle of turn, area ratio of 2.16 and $\mathrm{Re}_{\text {in }}$ of $8.163 \times 10^{5}$ is proposed to be the most optimum configuration to produce pressure recovery coefficient, $C p=0.399$ and flow uniformity index, $\sigma_{\text {out }}=3.630 \mathrm{~m} / \mathrm{s}$. Figure 10 shows the quality of flow obtained with no separation occurred and the flow is distributed well at the outlet.
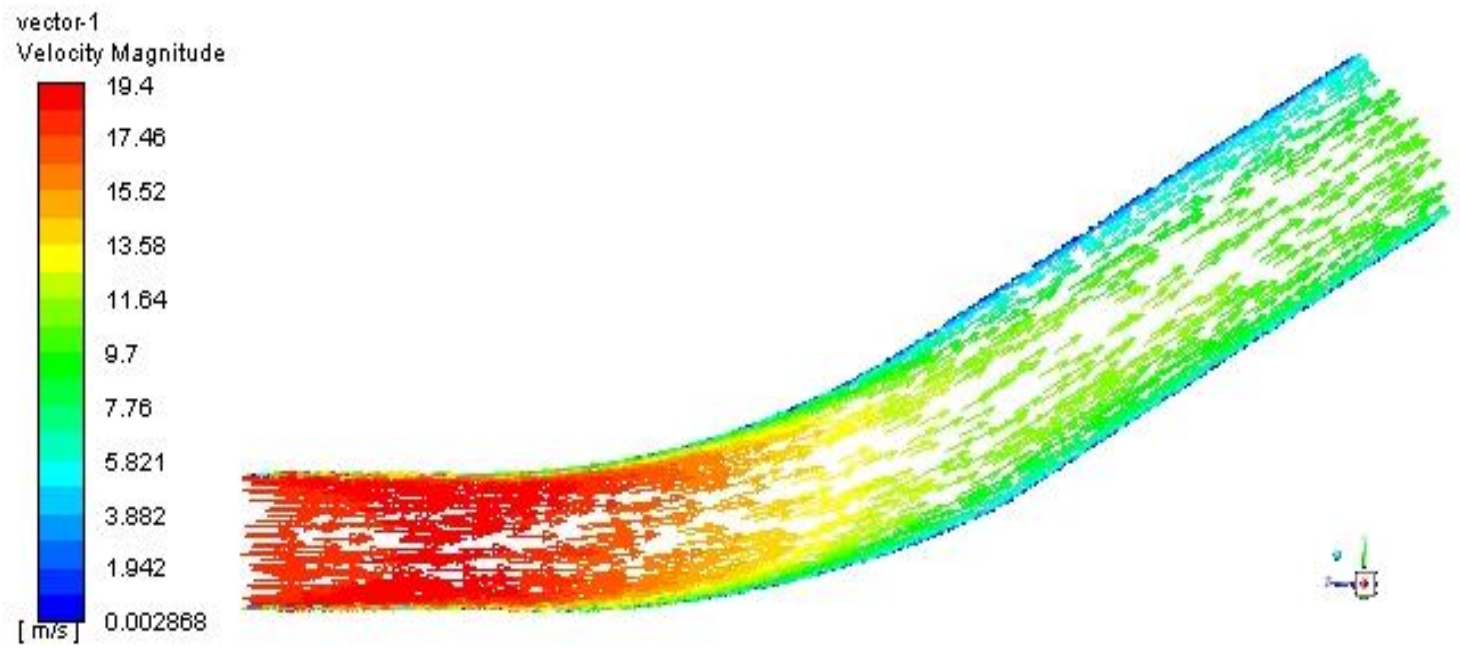

(a) 

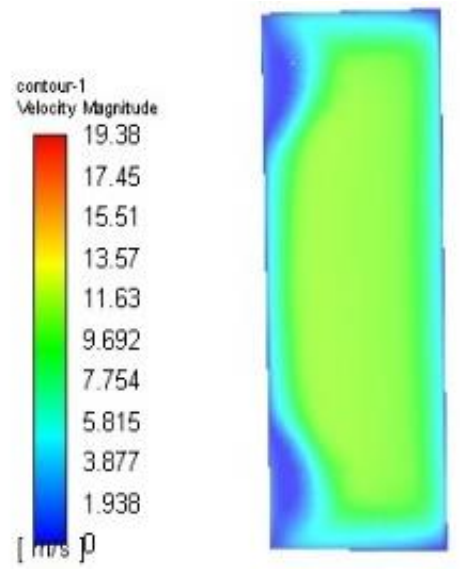

(b)

Fig. 10. (a) Velocity vector and (b) outlet velocity contour of a curve diffuser with $\Delta \phi=30^{\circ}$, $A R=2.16$ and $R_{\text {in }}=8.163 \times 10^{5}$

\section{Conclusions}

In conclusion, the effects of turning angle configured with area ratio and inflow Reynolds Number have been successfully investigated with the most optimum configuration been proposed. The main findings are highlighted as follows:

i. An increase of turning angle from $30^{\circ}$ to $180^{\circ}$ disrupts the pressure recovery and flow uniformity of respectively $85.71 \%$ and $45.84 \%$.

ii. Presences of flow separation, dispersion of core flow and secondary flow vortices are found to significantly affect the performance of the curve diffuser regardless of its turning angle, area ratio and inflow Reynolds Number.

iii. The minimum turning angle of $30^{\circ}$, an area ratio of 2.16 and inflow Reynolds Number of $8.163 \times 10^{4}$ provides the most promising pressure recovery, $C_{p}=0.399$ and flow uniformity index, $\sigma_{\text {out }}=3.630 \mathrm{~m} / \mathrm{s}$.

\section{Acknowledgement}

This research was supported by Ministry of Higher Education through Fundamental Research Grant Scheme (FRGS/1/2018/TK03/UTHM/02/7). We also want to thank to the Universiti Tun Hussein Onn Malaysia (UTHM) for providing facilities to conduct the work.

\section{References}

[1] Fox, Robert W., and S. J. Kline. "Flow regimes in curved subsonic diffusers." J. Fluids Eng. Trans. ASME 84, (1962): 303-312. https://doi.org/10.1115/1.3657307

[2] Sedlár, Milan, and Jaromır Prihoda. "Investigation of flow phenomena in curved channels of rectangular crosssection." Engineering Mechanics 14, no. 6 (2007): 387-397.

[3] Chong, T. P., P. F. Joseph, and P. O. A. L. Davies. "A parametric study of passive flow control for a short, high area ratio 90deg curved diffuser." Journal of Fluids Engineering 130, no. 11 (2008). https://doi.org/10.1115/1.2969447

[4] Nguyen, Cuong K., Tuan D. Ngo, Priyan A. Mendis, and John CK Cheung. "A flow analysis for a turning rapid diffuser using CFD." J. Wind Eng 108, (2006).

[5] Nordin, Normayati, Vijay R. Raghavan, Safiah Othman, and Zainal Ambri Abdul Karim. "Compatibility of 3-D turning diffusers by means of varying area ratios and outlet-inlet configurations." ARPN Journal of Engineering and Applied Sciences 7, no. 6 (2012): 708-713.

[6] Nordin, Normayati, Vijay R. Raghavan, Safiah Othman, and Zainal Ambri Abdul Karim. "Numerical investigation of turning diffuser performance by varying geometric and operating parameters." In Applied Mechanics and 
Materials, vol. 229, pp. 2086-2093. Trans Tech Publications Ltd, 2012. https://doi.org/10.4028/www.scientific.net/AMM.229-231.2086

[7] Nordin, Normayati, Zainal Ambri Abdul Karim, Safiah Othman, and Vijay R. Raghavan. "The performance of turning diffusers at various inlet conditions." In Applied Mechanics and Materials, vol. 465, pp. 597-602. Trans Tech Publications Ltd, 2014. https://doi.org/10.4028/www.scientific.net/AMM.465-466.597

[8] Nordin, Normayati, Zainal Ambri Abdul Karim, Safiah Othman, and Vijay R. Raghavan. "Effect of varying inflow reynolds number on pressure recovery and flow uniformity of 3-D turning diffuser." In Applied Mechanics and Materials, vol. 699, pp. 422-428. Trans Tech Publications Ltd, 2015. https://doi.org/10.4028/www.scientific.net/AMM.699.422

[9] Nordin, Normayati, and SERI ISKANDAR BANDAR. "Performance investigation of turning diffusers at various geometrical and operating parameters." PhD diss., Universiti Teknologi PETRONAS, 2016.

[10] Tham, Wei Xian, Normayati Nordin, Azian Hariri, Nurul Fitriah Nasir, Norasikin Mat Isa, Musli Nizam Yahya, and Suzairin Md Seri. "Asymptotic computational fluid dynamic (ACFD) study of three-dimensional turning diffuser performance by varying angle of turn." International Journal of Integrated Engineering 11, no. 5 (2019): 109-118. https://doi.org/10.30880/ijie.2019.11.05.015

[11] Rasidi, Shamsuri, Suzairin Md Seri, Normayati Nordin, Muhammad Zahid Shariff, Nurul Fitriah Nasir, Sharifah Adzila, and Raudhah Othman. "Numerical Investigation of 180o Curved Diffuser Performance by Varying Geometrical and Operating Parameters." CFD Letters 12, no. 7 (2020): 100-109. https://doi.org/10.37934/cfdl.12.7.100109

[12] Huang, Lim Gim, Normayati Nordin, Lim Chia Chun, Nur Shafiqah Abdul Rahim, Shamsuri Mohamed Rasidi, and Muhammad Zahid Firdaus Shariff. "Effect of Turbulence Intensity on Turning Diffuser Performance at Various Angle of Turns." CFD Letters 12, no. 1 (2020): 48-61.

[13] Kumaraswamy, Rakesh, Karthikeyan Natarajan, and R. B. Anand. "CFD Analysis of Flow and Performance Characteristics of a $90^{\circ}$ curved Rectangular Diffuser: Effects of Aspect Ratio and Reynolds Number." International Journal of Turbo \& Jet-Engines (2019). https://doi.org/10.1515/tij-2019-0011

[14] Zhang, Wei-Li, Doyle D. Knight, and Don Smith. "Automated design of a three-dimensional subsonic diffuser." Journal of Propulsion and Power 16, no. 6 (2000): 1132-1140. https://doi.org/10.2514/6.2000-665

[15] Khong, Y. T., N. Nordin, S. M. Seri, A. N. Mohammed, A. Sapit, I. Taib, K. Abdullah, A. Sadikin, and M. A. Razali. "Effect of turning angle on performance of 2-D turning diffuser via Asymptotic Computational Fluid Dynamics." In IOP Conference Series: Materials Science and Engineering, vol. 243, no. 1, p. 012013. IOP Publishing, 2017. https://doi.org/10.1088/1757-899X/243/1/012013

[16] Shariff, Muhammad Zahid Firdaus, Normayati Nordin, Lim Chia Chun, Shamsuri Mohamed Rasidi, Raudhah Othman, and Sharifah Adzila. "Development of Performance Correlations using ACFD Method for 2-D Curved Diffuser." CFD Letters 12, no. 8 (2020): 1-16. https://doi.org/10.37934/cfdl.12.8.116

[17] El-Askary, W. A., and M. Nasr. "Performance of a bend-diffuser system: Experimental and numerical studies." Computers \& fluids 38, no. 1 (2009): 160-170. https://doi.org/10.1016/i.compfluid.2008.01.003

[18] Suryadi, Aji. "Compressor Piping Design Effect on Vibration Data." Journal of Advanced Research in Fluid Mechanics and Thermal Sciences 88, no. 1 (2021): 94-108. https://doi.org/10.37934/arfmts.88.1.94108

[19] Omar, Hossin, Suliman Alfarawi, Azeldin El-sawi, and Hassan Alobeidy. "Study the Effect of Baffle Spacing on Heat Transfer and Pressure Drop in Shell and Tube Heat Exchanger." Journal of Advanced Research in Numerical Heat Transfer 6, no. 1 (2021): 22-30.

[20] Gan, Guohui, and Saffa B. Riffat. "Measurement and computational fluid dynamics prediction of diffuser pressureloss coefficient." Applied energy 54, no. 2 (1996): 181-195. https://doi.org/10.1016/0306-2619(95)00078-X

[21] Wang, Yi-Chun, Jui-Cheng Hsu, Ping-Chi Kuo, and Yung-Chun Lee. "Loss characteristics and flow rectification property of diffuser valves for micropump applications." International Journal of Heat and Mass Transfer 52, no. 12 (2009): 328-336. https://doi.org/10.1016/i.ijheatmasstransfer.2008.06.010

[22] Mohamed, Mohamed S., Berge Djebedjian, and M. M. Rayan. "Experimental and Numerical Studies of Flow in a Logarithmic Spiral Curved Diffuser." In Proceedings, FEDSM '2000, ASME Fluids Engineering Summer Meeting Conference, pp. 1-8. 2000.

[23] Gopaliya, Manoj Kumar, and K. K. Chaudhary. "CFD analysis of performance characteristics of Y-shaped diffuser with combined horizontal and vertical offsets." Aerospace Science and Technology 14, no. 5 (2010): 338-347. https://doi.org/10.1016/i.ast.2010.02.008

[24] Gopaliya, Manoj Kumar, Piyush Goel, Sunil Prashar, and Anil Dutt. "CFD analysis of performance characteristics of S-shaped diffusers with combined horizontal and vertical offsets." Computers \& fluids 40, no. 1 (2011): $280-290$. https://doi.org/10.1016/i.compfluid.2010.09.027

[25] El-Askary, W. A., and M. Nasr. "Performance of a bend-diffuser system: Experimental and numerical studies." Computers \& fluids 38, no. 1 (2009): 160-170. https://doi.org/10.1016/i.compfluid.2008.01.003 